\title{
Phase behavior of the polymer/drug system PLA/DEET: Effect of PLA molar mass on subambient liquid-liquid phase separation
}

Chanita Sungkapreecha ${ }^{1}$, Mark J. Beily ${ }^{2}$, Jörg Kressler ${ }^{2}$, Walter W. Focke ${ }^{3}$, and René

$$
\text { Androsch }{ }^{1 *}
$$

1 Interdisciplinary Center for Transfer-oriented Research in Natural Sciences, Martin Luther University Halle-Wittenberg, 06099 Halle/Saale, Germany

2 Institute of Chemistry, Martin Luther University Halle-Wittenberg, D-06099 Halle/Saale, Germany

3 UP Institute of Sustainable Malaria Control and Institute of Applied Materials, Department of Chemical Engineering, University of Pretoria, Private Bag X20, Hatfield 0028, South Africa

Graphical abstract

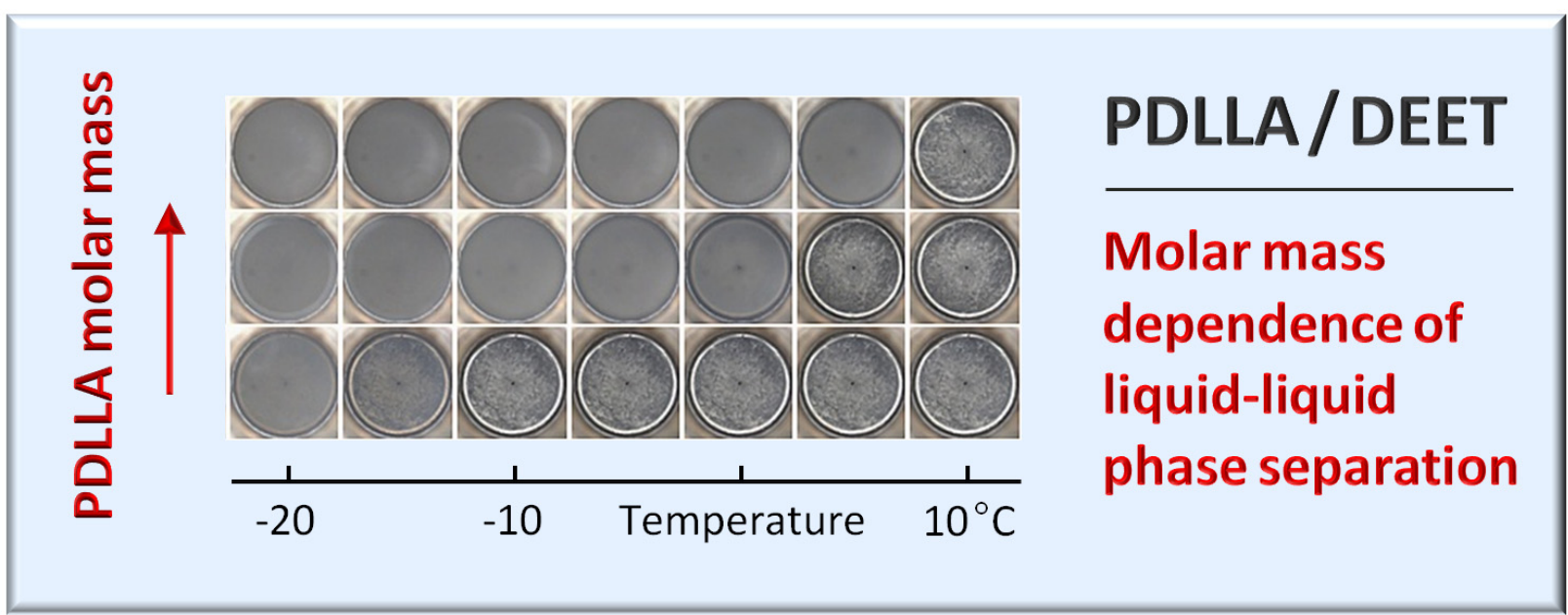

* rene.androsch@iw.uni-halle.de 


\begin{abstract}
The phase behavior of binary mixtures of non-crystallizable racemic poly (D, L-lactic acid) (PDLLA) and the mosquito-repellent/drug $N, N$-diethyl-3-methylbenzamide (DEET) was analyzed with respect to the effect of the polymer molar mass on the liquid-liquid (L-L) phase separation characteristics, by cloud-point measurements and differential scanning calorimetry. The PDLLA/DEET system shows a subambient upper critical solution temperature (UCST), with the critical temperature decreasing and critical polymer concentration increasing with decreasing molar mass of PDLLA. The obtained L-L phase separation curves were used to estimate the temperature-dependence of the interaction parameter, confirming that the enhanced miscibility of the system components in case of low molar mass PDLLA is due to increased entropy of mixing.
\end{abstract}

Keywords: PLA/DEET phase diagram; liquid-liquid phase separation, Flory-Huggins interaction parameter 


\section{Introduction}

Poly (lactic acid) (PLA) is an environmentally-friendly, linear and aliphatic polyester which is produced from annually renewable resources. It is therefore gaining increasing interest as a potential replacement for petroleum-based polymers in many areas of application. Specific uses of PLA are related to its compostability/degradability, food safety compliance, and biocompatibility/bioresorbability. As such, PLA can also be applied in the fields of implants, tissue engineering, or as a carrier for controlled drug delivery [1-7].

Scaffolds for tissue regeneration [8] or for drug delivery [9] are often produced by a thermally-induced phase separation process (TIPS). In this process a polymer solution transforms into a multiphase system with the transition controlled by temperature $[10,11]$. Separation of the solution into polymer-rich and solvent-rich phases may occur by crystallization, being then classified as a solid-liquid (S-L) separation, or by liquid-liquid (LL) demixing $[12,13]$. A recent study showed that PLA dissolves at elevated temperature in $\mathrm{N}, \mathrm{N}$-diethyl-3-methylbenzamide (DEET) and that a microporous scaffold-like structure can be obtained via S-L demixing [14]. DEET is known as a highly effective mosquito repellent $[15,16]$, and it has been proposed that the system PLA/DEET can be used as a controlledrelease device. In such a device, the TIPS process causes the active (DEET) to be trapped inside a microporous polymer matrix (PLA). The repellent can then be gradually delivered to the environment, with the evaporation rate expected to be adjustable by the crystallizationcontrolled scaffold morphology. A similar approach of forming a microporous polymer structure via TIPS for the system polyethylene/citronellal employed instead L-L demixing followed by crystallization [17].

With the study presented here, we attempt to further explore the phase behavior of the mosquito repellent-delivery system PLA/DEET. In previous work, solvent (DEET) rich solutions of crystallizable poly (L-lactic acid) (PLLA) were prepared and S-L demixing on cooling the solutions by crystallization of the polymer component was analyzed [14]. For observation of L-L demixing temperatures in the present study, a non-crystallizable random copolymer containing L- and D-units (PDLLA) was employed, with the advantage that the LL phase separation then cannot be superimposed/masked by crystallization. It has been found that for the intended use of PLA as DEET drug carrier, crystallizable grades must be used since the $\mathrm{L}-\mathrm{L}$ phase separation temperature is slightly below ambient; in other words noncrystallizable PLA forms a homogeneous solution with DEET at ambient temperature. For 
analysis of L-L demixing a PDLLA grade with a specific mass-average molar mass of 262 $\mathrm{kDa}$ was used. However, according to Huggins [18] and Flory [19], the molar mass is expected to control the thermodynamics of the phase behavior via its effect on the entropy of mixing. The system PLA/DEET exhibits an upper critical solution temperature (UCST), and for such systems it is in general predicted that the critical temperature decreases with decreasing polymer molar mass, concomitant with a shift of the critical polymer concentration to higher values [20,21]. Examples of systematic analyses of the effect of the polymer molar mass on the UCST-behavior include studies on the systems polyisobutylene/diisobutyl ketone [20], polystyrene/cyclohexane [20-22], poly (ethylene glycol)/water [22], or polypropylene/diphenyl ether [23].

It has been shown that porous PLA for application as scaffold or membrane can be obtained via TIPS, using organic solvents such as dioxane/water [10, 24], chloroform/methanol [25], tetrahydrofuran (THF) [26, 27], or dichloromethane/hexane [28]. In neither case the effect of molar mass of PLA on the L-L demixing behavior was explored, even though this parameter may have advantageously been used to tailor the demixing characteristics and with that the morphology of the polymer phase. The present study is therefore a first attempt to explore the effect of the molar mass of a PLA-based polymer/solvent system on the L-L phase separation in the specific system PLA/DEET. It is considered as a continuation of our prior research efforts to explore possible applications of that system as a drug-delivery device, focusing here on identification of a critical molar mass needed to shift the UCST to above ambient, being a prerequisite for convenient preparation and usage of such device. Furthermore, compositiondependent $\mathrm{L}-\mathrm{L}$ demixing temperature will be used to obtain estimates of the Flory-Huggins interaction parameter.

\section{Experimental}

\section{Materials and preparation}

The study was performed using non-crystallizable ester-terminated random D-/L-lactic acid copolymers (PDLLA) of different molar mass, synthesized from a racemic mixture of L- and D-stereoisomers, and obtained from Evonik Nutrition \& Care GmbH (Germany) [29]. The molar mass of the various PDLLA samples was determined by Gel Permeation Chromatography (GPC) using a Viscotek GPCmax VE2001 system with a Viscotek VE3580 refractive index detector. A buffer solution of dimethylformamide (DMF) containing $10 \mathrm{mM}$ lithium bromine was used as an eluent, with a flow rate of $1 \mathrm{~mL} \mathrm{~min}^{-1}$. The samples were 
dissolved in the mobile phase at ambient temperature and injected into a $25{ }^{\circ} \mathrm{C}$ thermostated PSS PolarSil GPC column with a length and diameter of $300 \mathrm{~mm}$ and $8 \mathrm{~mm}$, respectively. The particle size and the porosity were $5 \mu \mathrm{m}$ and $300 \AA$, respectively. The measurements were performed at $25^{\circ} \mathrm{C}$ using a PMMA standard for calibration. Results of the GPC analysis are shown together with intrinsic-viscosity data in the list of samples in Table 1. $N, N$-diethyl3-methylbenzamide (DEET) with a purity of $97 \%$ was obtained from Sigma-Aldrich and used as received without further purification [30]. The PDLLA copolymers were obtained as flakes and were dissolved in DEET inside closed $4 \mathrm{~mL}$ glass vials within few minutes at 80 $100{ }^{\circ} \mathrm{C}$, using a Thermo Scientific Reacti-Therm block heater/stirrer. Solutions with a polymer concentration of $2.5,5,10,20,25$, and $30 \% \mathrm{~m}$ were prepared.

Table 1: Intrinsic viscosity (IV) (measured at $25^{\circ} \mathrm{C}$ in chloroform) [29], mass-average molar mass $\left(M_{\mathrm{w}}\right)$, number-average molar mass $\left(M_{\mathrm{n}}\right)$, and polydispersity (PD) of the PDLLA samples used in the present study. The sample code is adapted from [29].

\begin{tabular}{lllll}
\hline Sample code & IV $\left(\mathbf{d L ~} \mathbf{g}^{-\mathbf{1}}\right)$ & $\boldsymbol{M}_{\mathbf{w}}(\mathbf{k D a})$ & $\boldsymbol{M}_{\mathbf{n}}(\mathbf{k D a})$ & PD (-) \\
\hline R203S & 1.40 & 49 & 24 & 2.0 \\
R205S & 0.64 & 177 & 80 & 2.2 \\
R207S & 0.31 & 262 & 169 & 1.6 \\
\hline
\end{tabular}

\section{Instrumentation}

Differential scanning calorimetry (DSC): DSC was employed for calorimetric analysis of LL phase separation temperatures of PDLLA/DEET systems. Measurements were performed using a calibrated heat-flux DSC 1 from Mettler-Toledo, operated in conjunction with a Huber TC100 intracooler. The furnace was purged with nitrogen gas at a flow rate of $60 \mathrm{~mL}$ $\min ^{-1}$. Samples were taken from freshly prepared solutions while stirred in the reactor block at $50{ }^{\circ} \mathrm{C}$, using a spatula to transfer a droplet with a mass of $30-35 \mathrm{mg}$ into $40 \mu \mathrm{L}$ aluminum pans, which then were closed with an aluminum lid. The solutions were heated to $50{ }^{\circ} \mathrm{C}$ and kept at this temperature for $2 \mathrm{~min}$, before cooling at a rate of $5 \mathrm{~K} \mathrm{~min}^{-1}$. Samples were used multiple times, with absence of evaporation of the solvent checked after each cooling scan, by measuring the sample mass.

Cloud point measurement: PDLLA/DEET solutions were put in open $40 \mu \mathrm{L}$ Mettler-Toledo aluminum crucibles and cooled from 50 to $-40{ }^{\circ} \mathrm{C}$ at a rate of $1 \mathrm{~K} \mathrm{~min}^{-1}$, using a calibrated Mettler-Toledo DSC 1 as a temperature controller. The measuring cell was purged with nitrogen gas at a flow rate of $60 \mathrm{~mL} \mathrm{~min}^{-1}$ and was covered with a transparent lid allowing 
observation of the sample using a Navitar objective lens and a digital camera. Images were captured every $30 \mathrm{~s}$, which corresponds a temperature resolution of $0.5 \mathrm{~K}$. All cloud point measurements were repeated at least twice to gain information about the reproducibility of the results.

\section{Results and discussion}

Cloud points of PDLLA/DEET solutions were analyzed using a DSC with a transparent furnace lid during cooling at a rate of $1 \mathrm{~K} \mathrm{~min}^{-1}$ from 50 to $-40{ }^{\circ} \mathrm{C}$. As an example, Figure 1 shows selected photographs taken at different temperatures between $10^{\circ} \mathrm{C}$ and $-30{ }^{\circ} \mathrm{C}$ on samples containing $10 \mathrm{~m} \%$ PDLLA with mass-average molar masses of $49 \mathrm{kDa}$ (top row), $177 \mathrm{kDa}$ (center row), and $262 \mathrm{kDa}$ (bottom row). The images taken at $10{ }^{\circ} \mathrm{C}$ reveal the presence of homogeneous solutions for all samples containing PDLLA of different molar mass, as the base of the aluminum pan employed as a container is clearly visible; note that the sample height/liquid level is about $2 \mathrm{~mm}$. With decreasing temperature, the PDLLA/DEET solutions gradually turn cloudy/non-transparent, proving L-L phase separation. Most important, however, is the observation that the temperature of $\mathrm{L}-\mathrm{L}$ demixing decreases with decreasing molar mass. For the samples containing PDLLA with molar masses of 49, 177 , and $262 \mathrm{kDa}$, first sign of turbidity is detected at temperatures of, roughly, $-15,0$, and $5{ }^{\circ} \mathrm{C}$, respectively.

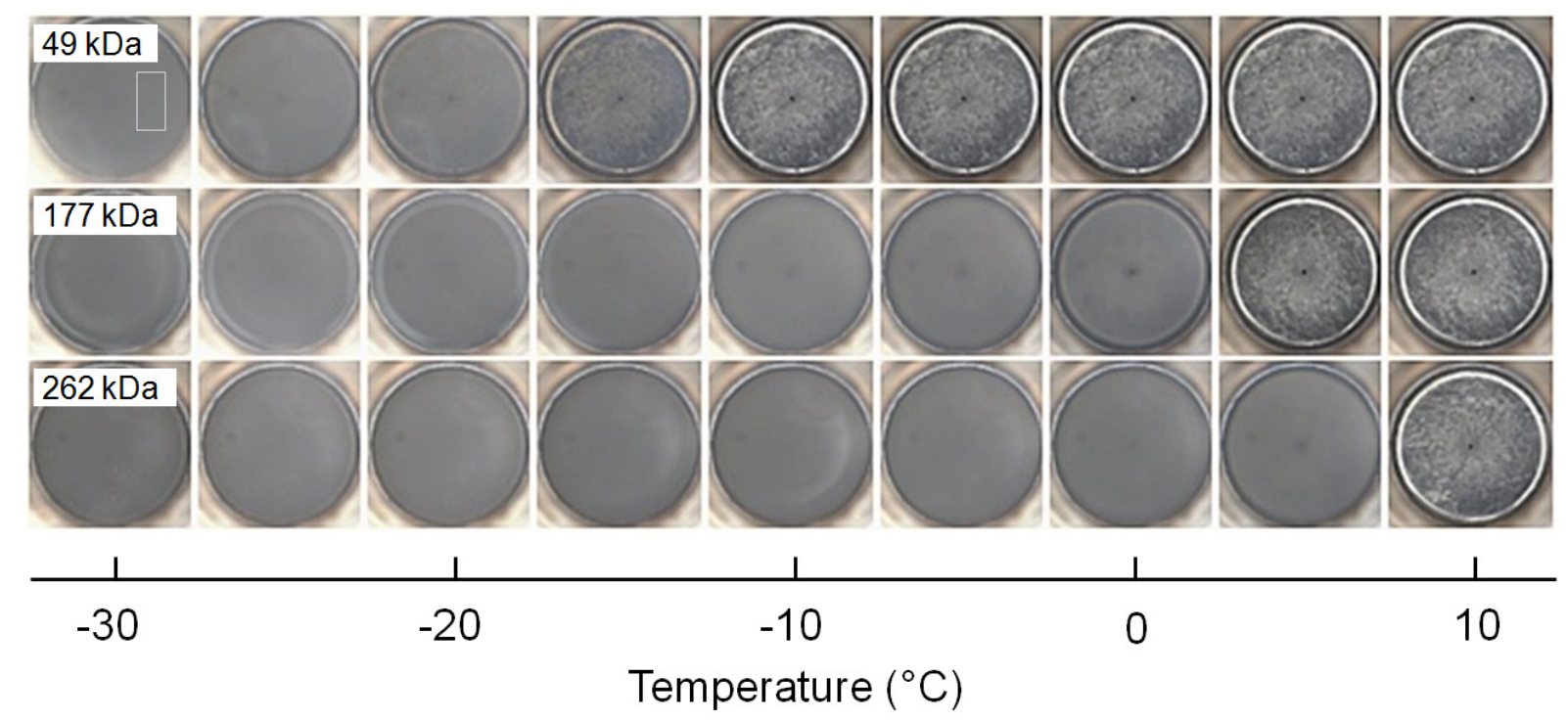

Figure 1: Optical macrographs taken on samples of the system PDLLA/DEET during cooling at $1 \mathrm{~K}$ $\mathrm{min}^{-1}$. The polymer concentration is $10 \mathrm{~m} \%$. With the top, center, and bottom rows are represented cooling experiments (to be read from right to left) using PDLLA with mass-average molar masses of 49,177 , and $262 \mathrm{kDa}$, respectively. 
Quantitative analysis of the turbidity of samples/images as shown in Figure 1 was done using the NIH-ImageJ 1.51 software [31]. Grayscale histograms were obtained for a pre-defined rectangular area of the image (see Figure 1, top left image), and evaluated regarding the width $(w)$ of the histogram. The latter was defined as the difference between the minimum and maximum non-zero grayscale value. For clear samples, large values of the histogramwidth were obtained while for opaque samples the distribution was narrow. The values of the histogram-width associated to a specific cooling experiment were 0,1 -normalized ( $\left.w_{\text {norm }}\right)$, and a turbidity index was then defined as $\left(1-w_{\text {norm }}\right)$, plotted as a function of temperature in Figure 2 for samples of the system containing PDLLA with a mass-average molar mass of $177 \mathrm{kDa}$. The data of Figure 2 reveal an onset of turbidity between 0 and $5{ }^{\circ} \mathrm{C}$ for samples containing $10 \mathrm{~m} \%$ or lesser amounts of PDLLA, and with increasing concentration of PDLLA the temperature of first sign of turbidity on cooling the solution at a rate of $1 \mathrm{~K} \mathrm{~min}^{-1}$ decreases to a value of close to $-10^{\circ} \mathrm{C}$ in case of the sample containing $30 \mathrm{~m} \%$ PDLLA. Such curves have been obtained for all systems of the present study containing PDLLA of different molar mass, with the onset of turbidity defined as temperature of $\mathrm{L}-\mathrm{L}$ demixing, as recommended in the literature $[32,33]$.

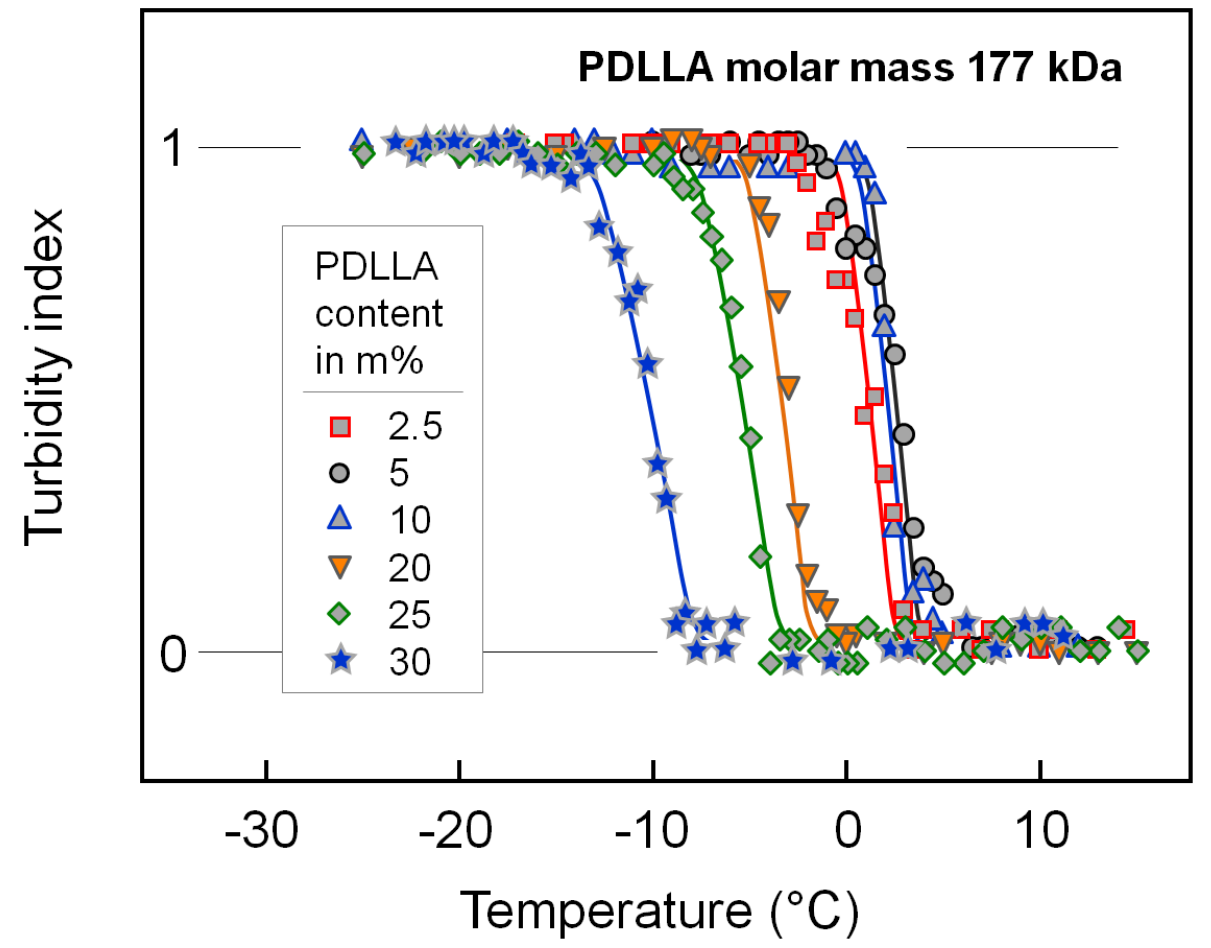

Figure 2: Turbidity index of the system PDLLA/DEET as a function of temperature. The massaverage molar mass of the polymer was $177 \mathrm{kDa}$. Data were extracted from images captured during cooling the initial solution at $1 \mathrm{~K} \mathrm{~min}^{-1}$ (see also Figure 1). The different data sets were obtained on samples of different polymer content between 2.5 and $30 \mathrm{~m} \%$, as indicated in the legend. 
It is worthwhile noting that demixing temperatures were additionally measured on cooling at $1,5,10$, and $20 \mathrm{~K} \mathrm{~min}^{-1}$. This, however, led only to a minor decrease of the transition temperature with increasing cooling rate; dissolution temperatures obtained on subsequent heating revealed the expected demixing/dissolution hysteresis [22, 34, 35].

Demixing of PDLLA/DEET solutions was furthermore analyzed by DSC. Figure 3 shows DSC curves recorded on cooling solutions of different content of PDLLA with a massaverage molar mass of $262 \mathrm{kDa}$ (upper set of curves) and of samples containing $20 \mathrm{~m} \%$ PDLLA of different molar mass of 49 (blue), 177 (green), and $262 \mathrm{kDa}$ (red) (lower set of curves) at a rate of $5 \mathrm{~K} \mathrm{~min}^{-1}$ from 50 to $-50{ }^{\circ} \mathrm{C}$. $\mathrm{L}-\mathrm{L}$ demixing of solutions is an exothermic transition which is detected in the DSC scans of Figure 3 with the upward directed small peak [36-38], being proportional in area to the PDLLA concentration. The onset of the transition/demixing is rather well defined, with the concentration dependence and molar-mass dependence emphasized with the gray lines in the upper and lower part of the Figure, respectively. As such the data in the upper part of Figure 3 suggest that the temperature of LL demixing passes through a maximum at a concentration of $5 \mathrm{~m} \%$ PDLLA, with a distinct decrease of the demixing temperature on increasing the polymer concentration. However, the DSC data obtained on samples containing a constant amount of PDLLA of $20 \mathrm{~m} \%$ in the solutions, shown in the lower part of Figure 3, demonstrate that the temperature of $\mathrm{L}-\mathrm{L}$ demixing significantly decreases with decreasing molar mass.

While the onset of demixing on cooling the solutions is straightforwardly detected by the sharp deviation from the heat-capacity baseline, the end of the transition is less well defined. We assume that with decreasing temperature in the two-phase area of the phase diagram the concentration of PDLLA and DEET in the two liquid phases is changing, causing minor exothermic heat flow until the system is eventually vitrifying at the glass transition temperature of the liquid phase containing more PDLLA. The glass transition temperatures of DEET and PDLLA are around $-75^{\circ} \mathrm{C}$ [39] and around $50{ }^{\circ} \mathrm{C}$, respectively, with the latter slightly decreasing with decreasing molar mass according to the Fox-Flory equation [40], from 53 to $43{ }^{\circ} \mathrm{C}$ in case of the PDLLA's with a number-average molar masses of 169 and 24 $\mathrm{kDa}$, respectively. With the knowledge of the glass transition temperatures of the components of the systems, prediction of vitrification with the assumption of a specific mixing rule is possible. In fact, the DSC curves of Figure 3 show a change of the curvature at low temperature which could be due to the glass transition. An in-depth analysis, however, is 
beyond the scope of the present study. As in case of cloud-point analyses, DSC curves were collected at various cooling rates between 1 and $20 \mathrm{~K} \mathrm{~min}^{-1}$ with the $\mathrm{L}-\mathrm{L}$ demixing temperatures remained unaffected [25].

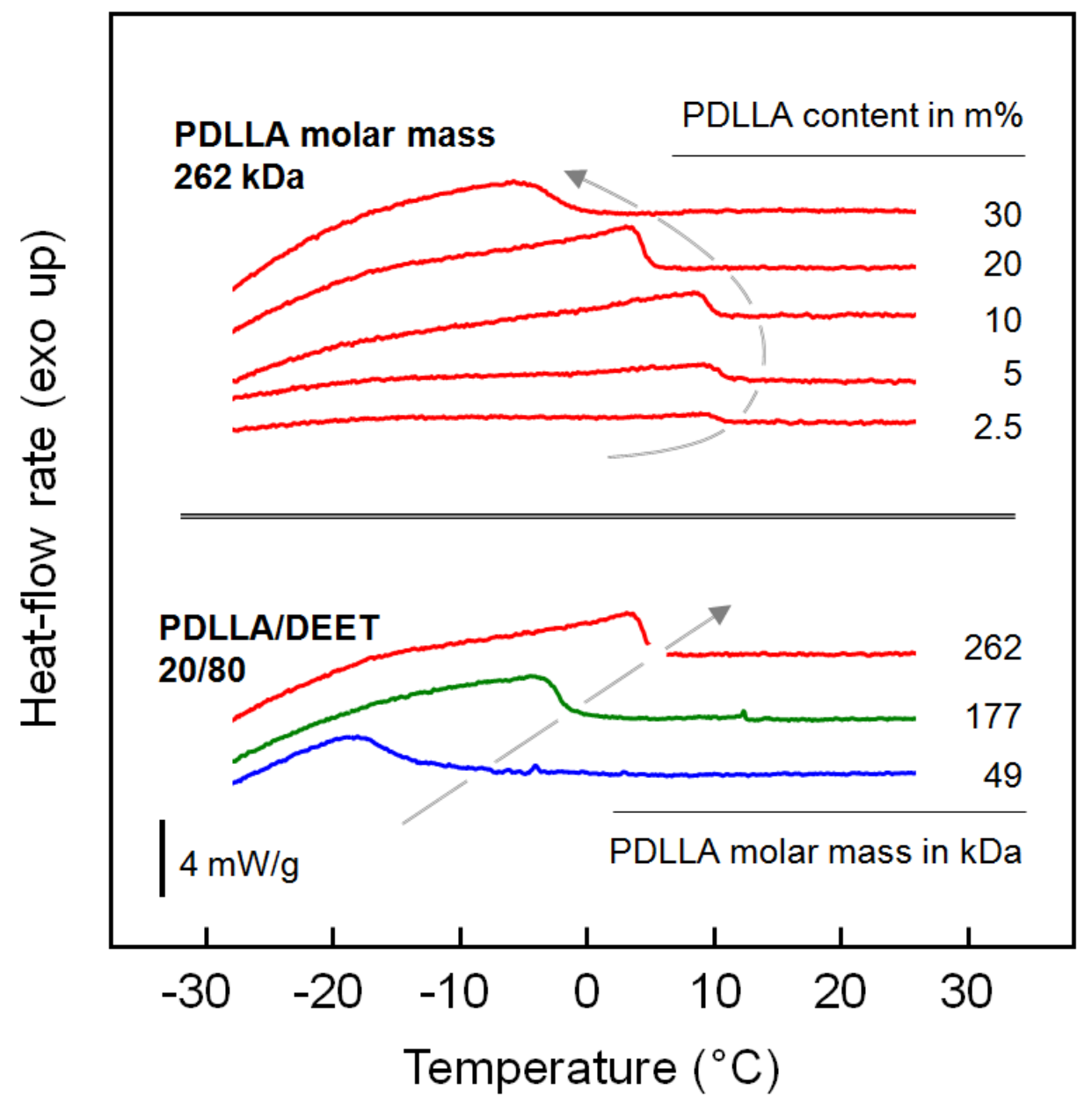

Figure 3: DSC cooling curves obtained on samples of the system PDLLA/DEET. In the upper part are shown data collected on samples containing different content of PDLLA with a mass-average molar mass of $262 \mathrm{kDa}$ while in the lower part are shown data of samples containing $20 \mathrm{~m} \%$ PDLLA of different mass-average molar mass of 49 (blue), 177 (green), and $262 \mathrm{kDa}$ (red). Exothermic heat flow is directed upwards. Data were collected at a rate of temperature change of $5 \mathrm{~K} \mathrm{~min}^{-1}$. The upper part is adapted from [14], Copyright (2017), with permission from Elsevier.

Temperatures of demixing of PDLLA/DEET solution are plotted as a function of the concentration of PDLLA in Figure 4. The blue, green, and red symbols/lines refer to systems containing PDLLA with mass-average molar masses of 49, 177, and $262 \mathrm{kDa}$, respectively. Squares and triangles refer to data which were obtained by cloud-point measurements (see Figures 1 and 2) and DSC (Figure 3) on cooling at rates of 1 and $5 \mathrm{~K} \mathrm{~min}^{-1}$, respectively. The data of Figure 4 reveal UCST behavior for all systems, with the critical temperature and 
concentration depending on the molar mass of the employed PDLLA. However, in all systems investigated, demixing occurs at subambient temperature, regardless of the molar mass and PDLLA content; at room temperature all systems are homogeneous. This notwithstanding, the critical temperature increases and the critical concentration decreases systematically with increasing molar mass, revealing enhanced thermodynamic miscibility for PDLLA of low molar mass. This observation resembles fundamental studies about the effect of molar mass of the polymer component on the thermodynamic miscibility of polymer/solvent systems, and is assumed to be related to the entropy of mixing [20-23]. In other words, the upward shift of the phase-coexistence curves with increasing molar mass of the PDLLA component is not expected to be caused by a change in the enthalpy of mixing.

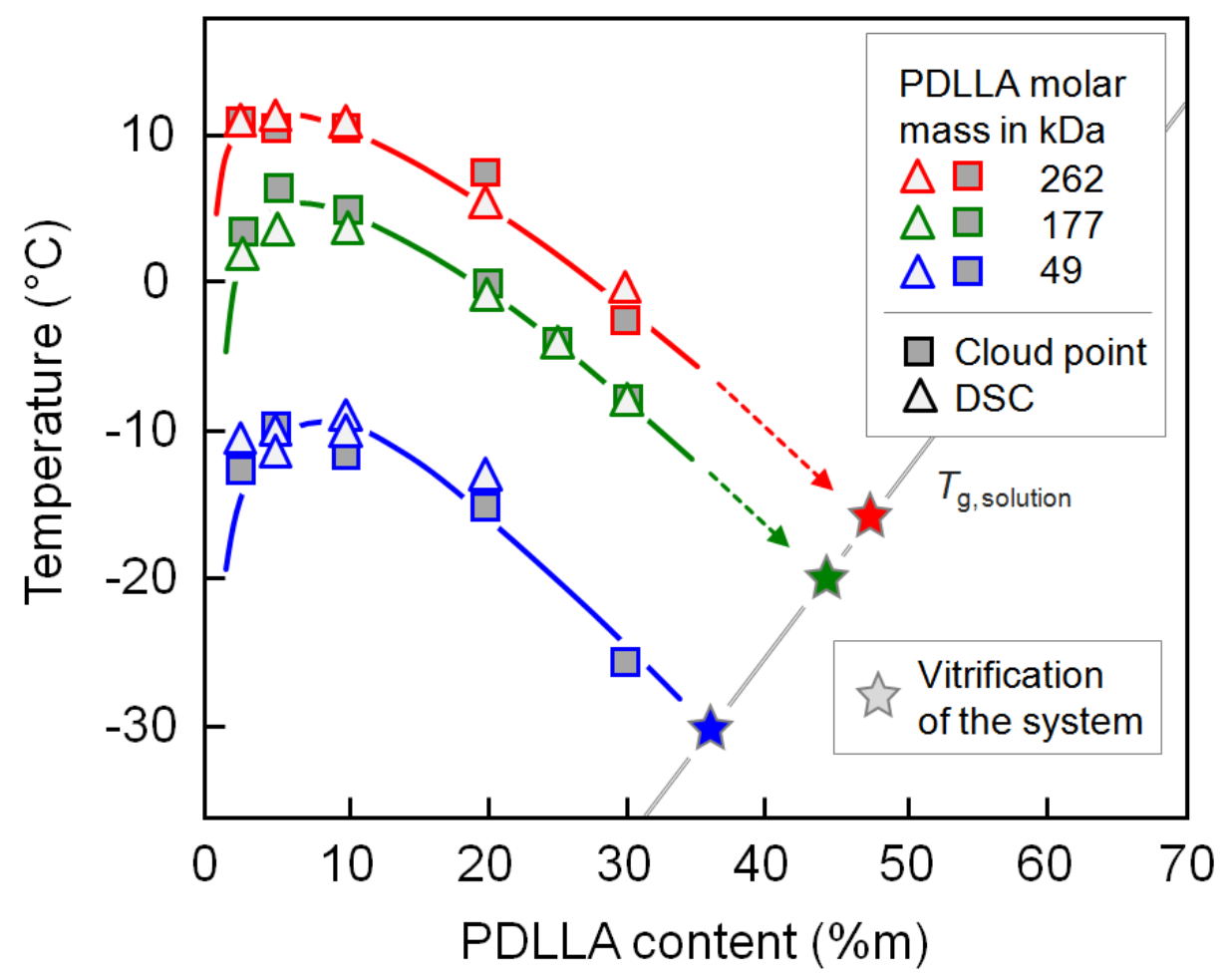

Figure 4: Demixing temperatures as a function of the concentration of PDLLA in binary mixtures with DEET. The blue, green, and red symbols/lines refer to systems containing PDLLA with mass-average molar masses of 49, 177, and $262 \mathrm{kDa}$, respectively. Data were obtained by cloudpoint measurements (squares) and DSC (triangles) on cooling at rates of 1 and $5 \mathrm{~K} \mathrm{~min}^{-1}$, respectively. The gray line represents the expected upper limit of the glass transition temperature of solutions $\left(T_{\mathrm{g}}\right.$, solution $)$ when assuming a linear mixing rule and the star-symbols the expected system-vitrification temperatures.

The gray line in Figure 4 represents the expected upper limit of the glass transition temperature of solutions ( $\left.T_{\mathrm{g} \text {, solution }}\right)$ when assuming a linear mixing rule; for simplicity it is 
drawn between $-75^{\circ} \mathrm{C}\left(T_{\mathrm{g}}\right.$, DEET $)$ and $50^{\circ} \mathrm{C}\left(T_{\mathrm{g}}\right.$, PDLLA $)$. It was inserted in order to predict the temperature at which the various systems containing PDLLA of different molar mass solidify by vitrification of the PDLLA-richer phase. On cooling PDLLA/DEET solutions, phase separation occurs when passing through the coexistence line, leading to the formation of two liquid phases/solutions. The PDLLA content in each of the two solutions depends on temperature and is given by intersection of the tie line with the phase transition curve. As such, with decreasing temperature, the PDLLA content in the PDLLA-richer liquid solution increases (see dashed arrows), and if the temperature is lower than given by the intersection

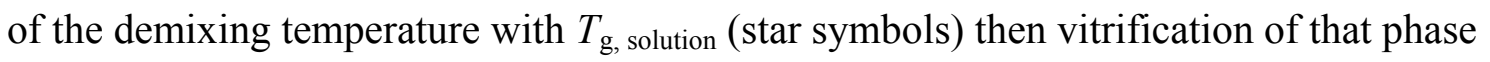
occurs. As outlined above on discussion of the data of Figure 3, the change of the curvature of the heat-flow rate curves on cooling the various systems supports the prediction of a decrease of the system-vitrification temperature with decreasing molar mass of the polymer component.

It is assumed that the shift of coexistence curves in the phase diagram of the various systems to lower temperature on decreasing the molar mass of the polymer component (see Figure 4) is due to an entropic effect and not due to a change of the FH-interaction parameter $\chi$. In order to prove/disprove this assumption, $\chi$-values for each of the three investigated systems were calculated. The approach suggested by Lloyd [41] was followed based on the relationships between the temperature-dependent tie-line phase compositions in the twophase area of the phase diagram to the interaction parameter according to equation (1):

$$
\begin{aligned}
& {\left[\left(\emptyset_{2}^{\beta}\right)^{2}-\left(\emptyset_{2}^{\alpha}\right)^{2}\right] x=\ln \left(\frac{1-\phi_{4}^{\alpha}}{1-\phi_{2}^{\beta}}\right)+\left(1-\frac{1}{\omega}\right)\left(\emptyset_{2}^{\alpha}-\emptyset_{2}^{\beta}\right)} \\
& v\left[\left(1-\Phi_{2}^{\sigma}\right)^{2}-\left(1-\Phi_{2}^{\gamma}\right)^{2}\right] x-1 \mu\left(\Phi_{2}^{\gamma} / \Phi_{2}^{\sigma \alpha}\right)+(v-1)\left(\Phi_{2}^{\alpha}-\Phi_{2}^{\sigma}\right)
\end{aligned}
$$

In equations (1a) and (1b), $\Phi_{2}^{\beta}$ and $\emptyset_{2}$ are the polymer-volume fractions of the polymer-richer and polymer-poorer phases, respectively, and $v$ is the ratio of the molar volume of the polymer to that of the solvent. In order to evaluate $\chi$, first the mass fraction of the polymer component in the system was converted in volume fraction, using PDLLA and DEET densities of $1.250 \mathrm{~g} \mathrm{~cm}^{-3}$ (P praA $)$ [42, 43] and $0.998 \mathrm{~g} \mathrm{~cm}^{-3}$ ( $\rho_{\text {DreT }}$ ) [30], respectively. The molar volume of PDLLA was calculated by dividing the number-average molar mass (see 
Table 1) with PpDLAa , and the molar mass of DEET of $191 \mathrm{~g} \mathrm{~mol}^{-1}$ with PDEZT , yielding $v$ values of 101, 336, and 707 for the systems containing PDLLA with number-average molar masses of 24, 80, and $169 \mathrm{kDa}$, respectively. For each system, the interaction parameter was estimated at four temperatures, covering a temperature range of roughly $10 \mathrm{~K}$, with the composition of the PDLLA content in the various phases estimated by the interpolation of data points of Figure 4. The interaction parameter is then plotted as a function of the inverse of the absolute temperature in Figure 5, revealing that in the temperature-range between the critical temperature and the vitrification temperature of the system $\chi$ is around 0.6 and that it slightly decreases with increasing temperature. All data points obtained on the various systems containing PDLLA of different molar mass fit a linear relationship, confirming that the different demixing temperatures (Figure 4) are due to a decrease in the entropy of mixing with increase in the PDLLA molar mass.

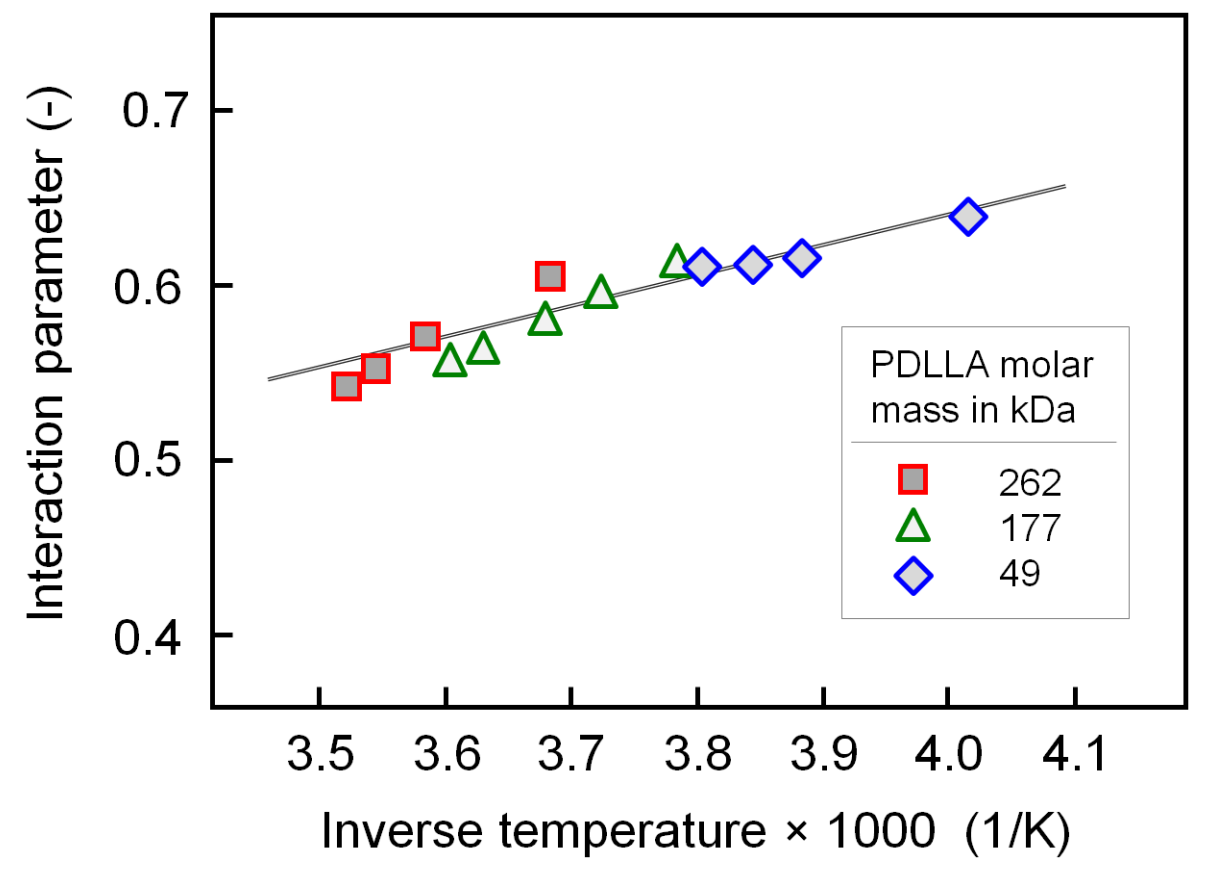

Figure 5: Interaction parameter $\chi$ of the polymer/solvent system PDLLA/DEET as a function of the inverse of the absolute temperature. The different symbols represent data associated to PDLLA with mass-average molar masses of 49, 177, and $262 \mathrm{kDa}$, respectively, and color-coding is in agreement with Figure 4. Only data calculated using equation (1a) are shown since equation (1b) yielded almost identical results. 


\section{Conclusions}

In this study the phase behavior of solvent-rich binary mixtures of non-crystallizable racemic poly (lactic acid) (PLA) and the mosquito-repellent/drug $N, N$-diethyl-3-methylbenzamide (DEET) was analyzed regarding the effect of the polymer molar mass on the liquid-liquid (LL) phase separation characteristics. Cloud-point measurements, employing a DSC for temperature control and a specific imaging system, as well as classical DSC analyses revealed that the PLA/DEET system shows a subambient upper critical solution temperature (UCST), with the critical temperature decreasing and critical polymer concentration increasing with decreasing molar mass of PLA. The obtained L-L phase separation curves were used to estimate the temperature-dependence of the Flory-Huggins interaction parameter, which suggests that the enhanced miscibility of PLA and DEET on decreasing the polymer molar mass is due to an increased entropy of mixing.

\section{Acknowledgments}

Financial support by Deutsche Forschungsgemeinschaft (DFG) (Grant AN 212/22) is greatly acknowledged. We thank Evonik Nutrition \& Care GmbH for kind supply of PDLLA Resomer R207S. 


\section{References}

[1] Auras R, Lim LT, Selke SEM, Tsuji H. Poly(lactic acid): Synthesis, structures, properties, processing, and applications. Wiley, Hoboken, 2010.

[2] Nair LS, Laurencin CT. Biodegradable polymers as biomaterials. Prog Polym Sci 2007;32:762-798.

[3] Barrows TH. Degradable implant materials: a review of synthetic absorbable polymers and their applications. Clinical materials 1986;1:233-257.

[4] Maurus PB, Kaeding CC. Bioabsorbable implant material review. Operative Techniques in Sports Medicine 2004;12:158-160.

[5] Sabir MI, Xu X, Li L. A review on biodegradable polymeric materials for bone tissue engineering applications. J Mater Sci 2009;44:5713-5724.

[6] Dhandayuthapan B, Yoshida Y, Maekawa T, Kumar DS. Polymeric scaffolds in tissue engineering application: a review. Int J Polym Sci 2011, Article ID 290602.

[7] Zhang Y, Chan HF, Leong KW. Advanced materials and processing for drug delivery: the past and the future. Adv Drug Delivery Reviews 2013;65:104-120.

[8] Ma PX. Scaffolds for tissue fabrication. Materials today 2004;7:30-40.

[9] Garg T, Singh O, Arora S, Murthy RSR. Scaffold: a novel carrier for cell and drug delivery. Critical Reviews ${ }^{\mathrm{TM}}$ in Therapeutic Drug Carrier Systems 2012, 29(1).

[10] Nam YS, Park TG. Porous biodegradable polymeric scaffolds prepared by thermally induced phase separation. J Biomed Mater Res 1999;47:8-17.

[11] Martínez-Pérez CA, Olivas-Armendariz I, Castro-Carmona JS, García-Casillas PE. Scaffolds for tissue engineering via thermally induced phase separation. Adv Regenerative Med: InTech 2011:275-294.

[12] Lloyd DR, Kinzer KE, Tseng HS. Microporous membrane formation via thermally induced phase separation. I. Solid-liquid phase separation. J Membr Sci 1990;52:239261.

[13] Lloyd DR, Kim SS, Kinzer KE. Microporous membrane formation via thermallyinduced phase separation. II. Liquid—liquid phase separation. J Membr Sci 1991;64:111.

[14] Sungkapreecha C, Iqbal N, Gohn AM, Focke WW, Androsch R. Phase behavior of the polymer/drug system PLA/DEET. Polymer 2017;126:116-125.

[15] Katz TM, Miller JH, Hebert AA. Insect repellents: Historical perspectives and developments. J Am Acad Dermatol 2008;58:865-871.

[16] Roberts JR, Reigart JR. Does anything beat DEET? Pediatr Ann 2004;33:443-453.

[17] Akhtar MU, Focke WW. Trapping citronellal in a microporous polyethylene matrix. Thermochim Acta 2015;613:61-65.

[18] Huggins ML. Solutions of long chain compounds. J Chem Phys 1941;9:440-440.

[19] Flory PJ. Thermodynamics of high polymer solutions. J Chem Phys 1942;10:51-61. 
[20] Shultz AR, Flory PJ. Phase equilibria in polymer-solvent systems ${ }^{1,2}$. J Am Chem Soc $1952 ; 74: 4760-4767$.

[21] Shultz AR, Flory PJ. Phase equilibria in polymer - solvent systems. II. Thermodynamic interaction parameters from critical miscibility data ${ }^{1}$. J Am Chem Soc 1953;75:38883892 .

[22] Bae YC, Lambert SM, Soane DS, Prausnitz JM. Cloud-point curves of polymer solutions from thermooptical measurements. Macromolecules 1991;24:4403-4407.

[23] Matsuyama H, Maki T, Teramoto M, Asano K. Effect of polypropylene molecular weight on porous membrane formation by thermally induced phase separation. $\mathrm{J}$ Membr Sci 2002;204:323-328.

[24] Hua FJ, Kim GE, Lee JD, Son YK, Lee DS. Macroporous poly(L-lactide) scaffold 1. Preparation of a macroporous scaffold by liquid-liquid phase separation of a PLLAdioxane-water system. J Biomed Mater Res 2002;63:161-167.

[25] van de Witte P, Boersma A, Esselbrugge H, Dijkstra P J, van den Berg JWA, Feijen J. Differential scanning calorimetry study of phase transitions in poly(lactide)-chloroform-methanol systems. Macromolecules 1996;29:212-219.

[26] Önder ÖC, Yilgör E, Yilgör I. Fabrication of rigid poly(lactic acid) foams via thermally induced phase separation. Polymer 2016;107:240-248.

[27] Yang F, Murugan R, Ramakrishna S, Wang X, Ma YX, Wang S. Fabrication of nanostructured porous PLLA scaffold intended for nerve tissue engineering. Biomaterials 2004;25:1891-1900.

[28] Rezabeigi E, Wood-Adams PM, Drew RAL. Isothermal ternary phase diagram of the polylactic acid-dichloromethane-hexane system. Polymer 2014;55:3100-3106.

[29] Product information, Evonik Nutrition \& Care GmbH, 2017; http://healthcare.evonik.com/product/healthcare/en/products/biomaterials/resomer/pages/medical-devices.aspx: accessed 07/09/2017.

[30] Product information, Sigma-Aldrich Chemie GmbH, 2017; http://www.sigmaaldrich.com/catalog/product/aldrich/d100951: accessed 07/09/2017.

[31] Schneider CA, Rasband WS, Eliceiri KW. NIH Image to ImageJ: 25 years of image analysis. Nature methods 2012:9:671-675.

[32] Klenin VJ, Shmakov SL. Features of phase separation in polymeric systems: Cloudpoint curves (discussion). Univ J Mater Sci 2013;1:39-45.

[33] Wohlfarth C. CRC Handbook of thermodynamic data of aqueous polymer solutions. CRC press, 2004.

[34] Mannella GA, La Carrubba V, Brucato V. Measurement of cloud point temperature in polymer solutions. Rev Sci Instrum 2013;84:75118.

[35] Lee HK, Myerson AS, Levon K. Nonequilibrium liquid-liquid phase separation in crystallizable polymer solutions. Macromolecules 1992;25:4002-4010. 
[36] Arnauts J, De Cooman R, Vandeweerdt P, Koningsveld R, Berghmans H. Calorimetric analysis of liquid - liquid phase separation. Thermochim Acta 1994;238:1-16.

[37] Arnauts J, Berghmans H, Koningsveld R. Structure formation in solutions of atactic polystyrene in trans-decalin. Makromol Chem 1993;194:77-85.

[38] Lu J, Carpenter K, Li R-J, Wang X-J, Ching C-B. Cloud-point temperature and liquidliquid phase separation of supersaturated lysozyme solution. Biophys Chem 2004;109:105-112.

[39] Griffin PJ, Sangoro JR, Wang Y, Holt AP, Novikov VN, Sokolov AP, Wojnarowska Z, Paluch M, Kremer F. Dynamic crossover and the Debye-Stokes-Einstein relation in liquid N, N-diethyl-3-methylbenzamide (DEET). Soft Matter 2013;9:10373-10380.

[40] Fox Jr TG, Flory PJ. Second-order transition temperatures and related properties of polystyrene. I. Influence of molecular weight. J Appl Phys 1950;21:581-591.

[41] McGuire KS, Laxminarayan A, Lloyd DR. A simple method of extrapolating the coexistence curve and predicting the melting point depression curve from cloud point data for polymer-diluent systems. Polymer 1994;35:4404-4407.

[42] Witzke DR. Introduction to properties, engineering, and prospects of polylactide polymer, Ph.D. thesis, Chemical Engineering, Michigan State University, 1997, page 389.

[43] Auras R, Harte B, Selke S. An overview of polylactides as packaging materials. Macromol Biosci 2004;4:835-864. 